\title{
Multivariate Analysis of Fruit Antioxidant Activities of Blackberry Treated with 1-Methylcyclopropene or Vacuum Precooling
}

\author{
Jian Li, Guowei Ma, Lin Ma, Xiaolin Bao, Liping Li, Qian Zhao, and Yousheng Wang (D) \\ Beijing Advanced Innovation Center for Food Nutrition and Human Health, Beijing Engineering and Technology Research Center of \\ Food Additives, Beijing Technology and Business University, Beijing 100048, China
}

Correspondence should be addressed to Yousheng Wang; wangys@btbu.edu.cn

Received 29 September 2017; Accepted 31 December 2017; Published 1 February 2018

Academic Editor: Ying Yang

Copyright (C) 2018 Jian Li et al. This is an open access article distributed under the Creative Commons Attribution License, which permits unrestricted use, distribution, and reproduction in any medium, provided the original work is properly cited.

\begin{abstract}
Effects of 1-methylcyclopropene (1-MCP) and vacuum precooling on quality and antioxidant properties of blackberries (Rubus spp.) were evaluated using one-way analysis of variance, principal component analysis (PCA), partial least squares (PLS), and path analysis. Results showed that the activities of antioxidant enzymes were enhanced by both 1-MCP treatment and vacuum precooling. PCA could discriminate 1-MCP treated fruit and the vacuum precooled fruit and showed that the radical-scavenging activities in vacuum precooled fruit were higher than those in 1-MCP treated fruit. The scores of PCA showed that $\mathrm{H}_{2} \mathrm{O}_{2}$ content was the most important variables of blackberry fruit. PLSR results showed that peroxidase (POD) activity negatively correlated with $\mathrm{H}_{2} \mathrm{O}_{2}$ content. The results of path coefficient analysis indicated that glutathione (GSH) also had an indirect effect on $\mathrm{H}_{2} \mathrm{O}_{2}$ content.
\end{abstract}

\section{Introduction}

Blackberries (Rubus spp.) are notable for their antioxidant activities, particularly due to their high contents of polyphenolic compounds, such as ellagic acid, quercetin, gallic acid, anthocyanins, and cyanidins, plus excellent contents of the antioxidant vitamins A and C [1-3]. However, blackberries have a short market life and the fruit quality is rapidly reduced after harvesting $[4,5]$.

Reactive oxygen species (ROS), like hydrogen peroxide $\left(\mathrm{H}_{2} \mathrm{O}_{2}\right)$ and superoxide $\mathrm{O}^{\circ-}$, could promote the oxidation of proteins and lipids and thus lead to fruit senescence and a decrease of fruit quality $[6,7]$. The antioxidant enzymes, including catalase (CAT), ascorbate peroxidase (APX), peroxidase (POD), and polyphenol oxidase (PPO), can prevent the accumulation of ROS and repair oxidative damage [8]. The antioxidants, such as polyphenolic compounds, also play an important role in scavenging excess ROS [9]. There are many correlated factors affecting the fruit quality. Hence, application of a multivariate technique to characterize the relationship among the antioxidant enzymes' activities, ROS levels, and antioxidant activities seems to be appropriate.
Principal component analysis (PCA) is a multivariate technique used to extract the important information from multivariate data [10]. Partial least squares (PLS) and path analysis can be especially useful to find the correlations between intercorrelated quantitative dependent variables. PLS has been used to predict the changes of quality of pasteurized pineapple juice during storage [11].

In this study, the quality and antioxidant parameters were collected from 1-MCP treated, vacuum precooled, and control fruit. Principal component analysis (PCA) was applied to evaluate the effect of 1-MCP and vacuum precooling on physiological properties of fruit. Correlations between quality and antioxidant parameters were studied through partial least squares (PLS) and path analysis.

\section{Materials and Methods}

2.1. Plant Material and Treatment. Blackberry fruit (Rubus spp. cv. Triple Crown) at the commercially mature stage was harvested from an orchard near Beijing. Fruit was sorted to eliminate damaged and diseased fruit and selected for uniformity in size and color. Fruit was randomized and 
divided into 3 lots for the following treatments: (1) untreated and referred to as the control and (2) treated with $5 \mu \mathrm{g} / \mathrm{L} \mathrm{1-}$ methylcyclopropene (1-MCP). Fruits were placed in sealed $250 \mathrm{~L}$ plastic chambers with 1-MCP powdered formulation (1250 $\mu \mathrm{g} 1-\mathrm{MCP}$ release) at room temperature for $24 \mathrm{~h}$ and (3) precooled in vacuum cooler at $10^{\circ} \mathrm{C}$ for $1 \mathrm{~h}$.

After the treatments, all the fruits were placed in $60 \mathrm{~cm} \times$ $37 \mathrm{~cm} \times 20 \mathrm{~cm}$ plastic containers and then stored at $0^{\circ} \mathrm{C}$ with $85-95 \%$ RH.

2.2. Fruit Quality Measurement. Flesh firmness of the fruit was measured using a texture analyzer (LFRA, Brookfield Ltd., USA). Fifteen fruits were measured at each sampling time.

Fruit of each treatment was distributed into three groups (30 fruit per group), and each group represented one replicate. The number of decayed fruits in each plastic container was counted and decay rate was calculated as percentage of decayed fruit versus total fruit.

2.3. Enzymatic Activity Analysis. For the ascorbate peroxidase (APX), peroxidase (POD), and polyphenol oxidase (PPO) activities assay, $10.0 \mathrm{~g}$ samples were thoroughly homogenized with $20 \mathrm{~mL}$ extracting buffer (pH $7.8100 \mathrm{mM}$ phosphate buffer containing 0.2 g polyvinylpolypyrrolidone) and centrifuged at $10,000 \times \mathrm{g}$ at $4^{\circ} \mathrm{C}$ for $20 \mathrm{~min}$, and the supernatant was collected and stored at $-80^{\circ} \mathrm{C}$ for further analysis.

APX activity was determined spectrophotometrically by monitoring the decline in absorbance at $290 \mathrm{~nm}$ as ascorbate was oxidized [12]. APX activity was expressed as $\mathrm{U} \cdot \mathrm{g}^{-1} \mathrm{FW}$.

POD activity was measured as the oxidation of guaiacol in the presence of $\mathrm{H}_{2} \mathrm{O}_{2}$ by measuring the absorbance at $460 \mathrm{~nm}$ [13]. The POD activity was expressed as $\mathrm{U} \cdot \mathrm{g}^{-1} \mathrm{FW}$.

PPO activity was measured according to the method of Jiang et al. and expressed as U.g ${ }^{-1}$ FW [13].

2.4. GSH Assays. Glutathione (GSH) was extracted from $10.0 \mathrm{~g}$ of the flesh tissue with $20 \mathrm{~mL}$ of ice-cold $5 \%$ trichloroacetic acid containing $5 \mathrm{mM}$ Ethylenediaminetetraacetic Acid (EDTA) and then centrifuged at $4^{\circ} \mathrm{C}$ for $10 \mathrm{~min}$ at $10,000 \times \mathrm{g}$. The supernatant was assayed for GSH according to the method of Guri, and the GSH content was expressed as $\mathrm{mg} \cdot 100 \mathrm{~g}^{-1} \mathrm{FW}[14]$.

2.5. $\mathrm{H}_{2} \mathrm{O}_{2}$ Assays. $\mathrm{H}_{2} \mathrm{O}_{2}$ was extracted by homogenizing $10.0 \mathrm{~g}$ of fruit tissue in $20 \mathrm{ml}$ of cold acetone and was measured according to the method of Brennan and Frenkel [15]. The $\mathrm{H}_{2} \mathrm{O}_{2}$ content was expressed as mg. $100 \mathrm{~g}^{-1} \mathrm{FW}$.

2.6. Antioxidant Activities Assay. For antioxidant activities assay, $10.0 \mathrm{~g}$ samples were thoroughly homogenized with $20 \mathrm{~mL}$ methyl alcohol and centrifuged at $10,000 \times \mathrm{g}$ at $4^{\circ} \mathrm{C}$ for $20 \mathrm{~min}$. The supernatant was used for antioxidant activities, total phenol, and total flavonoid concentration assays.

Total antioxidant activity was measured using ferric reducing antioxidant potential assay (FARP) [16]. The values were expressed as the concentration of antioxidants having a ferric reducing ability equivalent to that of $1 \mathrm{mmol} / \mathrm{L} \mathrm{FeSO}_{4}$.
Trolox equivalent antioxidant capacity (TEAC) was determined according to the method of Arts et al. [17]. 50\% of the 2,2'-Azinobis-(3-ethylbenzothiazoline-6-sulphonate) (ABTS) radical-scavenging activity is defined as one activity unit. TEAC activity was expressed as $\mathrm{U} \cdot \mathrm{g}^{-1} \mathrm{FW}$.

The 2,2-diphenylpicrylhydrazyl (DPPH) radical-scavenging activity was assayed by the method of Shon et al. [18]. $50 \%$ of the DPPH radical-scavenging activity is defined as an activity unit and the DPPH radical-scavenging activity was expressed as $\mathrm{U} \cdot \mathrm{g}^{-1} \mathrm{FW}$.

Superoxide anion scavenging activity was measured by Nitrotetrazolium Blue chloride (NBT) reduction method [19]. $50 \%$ of the superoxide anion scavenging activity is defined as an activity unit. Superoxide anion scavenging activity was expressed as $\mathrm{U} \cdot \mathrm{g}^{-1} \mathrm{FW}$.

Hydroxyl radical-scavenging activity is determined by the method of Shon et al. [18]. 50\% of the hydroxyl radicalscavenging activity is defined as an activity unit. Hydroxyl radical-scavenging activity was expressed as $\mathrm{U} \cdot \mathrm{g}^{-1} \mathrm{FW}$.

The total phenolic concentration of flesh extracts was measured using a modified Folin-Ciocalteu colorimetric method [20]. Absorbance was measured at $760 \mathrm{~nm}$ after $60 \mathrm{~min}$ at room temperature. The results were expressed as micrograms of gallic acid equivalents per gram of fresh weight.

The total flavonoid concentration of flesh extracts was determined using a colorimetric assay [20]. The absorbance of the solution versus a blank at $510 \mathrm{~nm}$ was measured after $60 \mathrm{~min}$. The results were expressed as micrograms of catechin equivalents per gram of fresh weight.

2.7. Statistical Analysis. All data were analyzed by one-way analysis of variance (ANOVA) with SPSS 11.0 statistical software. Significant differences were performed by a least significant difference method (LSD test, $P \leq 0.05$ ) for all treatments at different sampling times.

For multivariate analysis, data were centered and weighted by the inverse of the standard deviation of each variable in order to avoid dependence on measured units. Principal component analysis (PCA) and partial least squares (PLS) in this study were performed using Unscrambler 9.7 statistical software. Path analysis model was developed by DPS (v.8.01) software.

\section{Results and Discussion}

3.1. One-Way Analysis of Variance. 1-Methylcyclopropene (1$\mathrm{MCP})$ has been proved to slow down the ripening of some fruits $[21,22]$. In this work, the decay rate of blackberry fruit was reduced significantly $(P<0.05)$ by 1 -MCP treatment (Table 1). The antioxidant enzymes, polyphenol oxidase (PPO), in 1-MCP treated fruit were also higher than control. On the other hand, a higher firmness was observed with vacuum precooling compared to control after 38 days of storage. The PPO activities were also enhanced by vacuum precooling after storage at $0^{\circ} \mathrm{C}$ for 38 days. Our finding suggested that both 1-MCP and vacuum precooling treatment had a potential value in delaying the senescence of blackberries. 
TABLE 1: Changes of quality and reactive oxygen metabolism indexes in blackberries during postharvest storage with different treatments.

\begin{tabular}{|c|c|c|c|c|c|c|c|}
\hline & \multicolumn{7}{|c|}{ Days of storage } \\
\hline & \multicolumn{3}{|c|}{ Control } & \multicolumn{2}{|c|}{ 1-MCP } & \multicolumn{2}{|c|}{ Vacuum precooling } \\
\hline & Harvest & $21 \mathrm{~d}$ & $38 \mathrm{~d}$ & $21 \mathrm{~d}$ & $38 \mathrm{~d}$ & $21 \mathrm{~d}$ & $38 \mathrm{~d}$ \\
\hline Firmness & $21.38^{\mathrm{d}}$ & $12.33^{\mathrm{b}}$ & $6.09^{\mathrm{a}}$ & $15.00^{\mathrm{bc}}$ & $5.84^{\mathrm{a}}$ & $17.76^{\mathrm{bcd}}$ & $18.31^{\mathrm{cd}}$ \\
\hline Decay rate (\%) & $0.00^{\mathrm{a}}$ & $0.00^{\mathrm{a}}$ & $21.67^{\mathrm{c}}$ & $0.00^{\mathrm{a}}$ & $11.67^{\mathrm{b}}$ & $0.00^{\mathrm{a}}$ & $18.34^{\mathrm{c}}$ \\
\hline $\mathrm{H}_{2} \mathrm{O}_{2}(\mathrm{mg} / 100 \mathrm{~g} \mathrm{fw})$ & $6.28^{\mathrm{a}}$ & $16.76^{\mathrm{b}}$ & $23.52^{\mathrm{d}}$ & $18.92^{\mathrm{c}}$ & $31.76^{\mathrm{f}}$ & $16.99^{\mathrm{b}}$ & $26.22^{\mathrm{e}}$ \\
\hline GSH (mg/100 g fw) & $61.55^{\mathrm{d}}$ & $65.89^{\mathrm{e}}$ & $26.62^{\mathrm{a}}$ & $80.80^{\mathrm{f}}$ & $39.43^{c}$ & $97.02^{\mathrm{g}}$ & $35.22^{\mathrm{b}}$ \\
\hline $\operatorname{APX}(\mathrm{U} / \mathrm{g} \mathrm{fw})$ & $0.02^{\mathrm{a}}$ & $0.03^{\mathrm{a}}$ & $0.09^{c}$ & $0.05^{\mathrm{ab}}$ & $0.08^{\mathrm{bc}}$ & $0.02^{\mathrm{a}}$ & $0.04^{\mathrm{a}}$ \\
\hline POD (U/g fw) & $105.71^{\mathrm{b}}$ & $5.58^{\mathrm{a}}$ & $1.32^{\mathrm{a}}$ & $5.41^{\mathrm{a}}$ & $4.17^{\mathrm{a}}$ & $5.09^{\mathrm{a}}$ & $4.96^{\mathrm{a}}$ \\
\hline PPO (U/g fw) & $1.54^{\mathrm{f}}$ & $0.75^{\mathrm{b}}$ & $0.59^{\mathrm{a}}$ & $0.92^{\mathrm{c}}$ & $0.91^{\mathrm{c}}$ & $1.2^{\mathrm{e}}$ & $1.1^{\mathrm{d}}$ \\
\hline FRAP (U/g fw) & $45.43^{\mathrm{e}}$ & $30.04^{\mathrm{b}}$ & $36.30^{c}$ & $28.03^{\mathrm{a}}$ & $42.50^{\mathrm{d}}$ & $36.86^{c}$ & $48.96^{\mathrm{f}}$ \\
\hline TEAC (U/g fw) & $0.2232^{\mathrm{b}}$ & $0.1980^{\mathrm{a}}$ & $0.2172^{\mathrm{b}}$ & $0.2609^{c}$ & $0.3192^{\mathrm{f}}$ & $0.2937^{\mathrm{e}}$ & $0.2824^{\mathrm{d}}$ \\
\hline DPPH (U/g fw) & $31.74^{\mathrm{c}}$ & $30.51^{\mathrm{a}}$ & $31.24^{\mathrm{b}}$ & $31.73^{c}$ & $38.30^{\mathrm{e}}$ & $31.22^{\mathrm{b}}$ & $36.61^{\mathrm{d}}$ \\
\hline NBT (U/g fw) & $7.80^{\mathrm{a}}$ & $33.18^{\mathrm{e}}$ & $26.18^{\mathrm{c}}$ & $35.69^{f}$ & $24.25^{\mathrm{b}}$ & $36.96^{\mathrm{g}}$ & $30.77^{\mathrm{d}}$ \\
\hline Hydroxyl radical-scavenging activity (U/g fw) & $42.51^{\mathrm{f}}$ & $38.17^{\mathrm{a}}$ & $40.75^{\mathrm{e}}$ & $38.90^{\mathrm{b}}$ & $39.33^{\mathrm{c}}$ & $39.97^{\mathrm{d}}$ & $38.05^{\mathrm{a}}$ \\
\hline Total phenol ( $\mu \mathrm{g} / \mathrm{g})$ & $6.15^{\mathrm{a}}$ & $8.43^{\mathrm{c}}$ & $7.68^{\mathrm{b}}$ & $9.02^{\mathrm{d}}$ & $9.43^{\mathrm{f}}$ & $9.18^{\mathrm{e}}$ & $9.37^{\mathrm{f}}$ \\
\hline Total flavonoid $(\mu \mathrm{g} / \mathrm{g})$ & $9.93^{\mathrm{f}}$ & $8.15^{\mathrm{b}}$ & $7.28^{\mathrm{a}}$ & $9.18^{\mathrm{d}}$ & $9.37^{\mathrm{e}}$ & $8.57^{\mathrm{c}}$ & $9.01^{\mathrm{d}}$ \\
\hline
\end{tabular}

The different superscript letters in the same row indicated significant difference $(P<0.05)$.

The antioxidant activities can be characterized by TEAC, DPPH, FARP, and NBT radical-scavenging activities. Compared with vacuum precooling, at the end of storage, 1MCP treated fruit had higher TEAC and DPPH radicalscavenging activities but lower FARP and NBT radicalscavenging activities. So, it was difficult to compare the effect between 1-MCP and vacuum precooling. For this reason, the PCA model was performed.

3.2. Principal Component Analysis. The parameters in Table 1 were used to develop the PCA model. The first three PCs explained $89 \%$ of the variance in the data, which was high enough to represent all the variables. The score plot for PC1 versus PC2 (Figure 1(a)) clearly distinguished three groups defined by length of storage, indicating that storage time had a major influence on the quality and reactive oxygen metabolism parameters of blackberry fruit.

Following PC3, the 1-MCP treated fruit and the vacuum precooled fruit were discriminated (Figure 1(b)). The loading plot of the variables showed that the TEAC and DPPH radical-scavenging activities had a heavy load on the positive coordinate of PC3. So, PC3 could be defined by antioxidant activities. The vacuum precooled fruit had higher positive scores for PC3 than 1-MCP treated fruit. These results suggested that precooled fruit might have values larger than the mean of the antioxidant activities, while 1-MCP treated fruit had relatively lower values.

3.3. Partial Least Squares. $\mathrm{H}_{2} \mathrm{O}_{2}$ as signal molecule plays an important role inside plant bodies [23]. From the PCA study (Figure 1(a)), $\mathrm{H}_{2} \mathrm{O}_{2}$ content had a heavy load on the negative coordinate of $\mathrm{PCl}$, suggesting that $\mathrm{H}_{2} \mathrm{O}_{2}$ content was the most important variable of blackberry fruit. We chose $\mathrm{H}_{2} \mathrm{O}_{2}$ content as $X$ variable and the other parameters as $Y$ variable
TABLE 2: The result of path analysis taking $\mathrm{H}_{2} \mathrm{O}_{2}$ as dependent variable.

\begin{tabular}{lccccc}
\hline & GSH & APX & POD & DPPH & $\begin{array}{c}\text { Total } \\
\text { flavonoid }\end{array}$ \\
\hline Direct & 0.0441 & 0.2559 & -0.4243 & 0.6499 & -0.1618 \\
$\rightarrow$ GSH & & -0.0307 & 0.0037 & -0.0231 & 0.0101 \\
$\rightarrow$ APX & -0.178 & & -0.116 & 0.0959 & -0.1044 \\
$\rightarrow$ POD & -0.0359 & 0.1923 & & 0.0792 & -0.2541 \\
$\rightarrow$ DPPH & -0.3397 & 0.2436 & -0.1213 & & 0.2654 \\
$\rightarrow$ Total & -0.0371 & 0.066 & -0.0969 & -0.0661 & \\
flavonoid & & & & & \\
\hline
\end{tabular}

to develop the PLS model to obtain a closer understanding of the relation between them. $64 \%$ of $X$ variables explained $88 \%$ of the variability of $Y$ variables. Many studies have showed that the production of $\mathrm{H}_{2} \mathrm{O}_{2}$ increased when plants were exposed to various biotic and abiotic stresses [23]. Peroxidase (POD) can decompose $\mathrm{H}_{2} \mathrm{O}_{2}$ by oxidation of cosubstrates, such as phenolic compounds and antioxidants [24], which could explain why a strongly negative correlation between POD activity and $\mathrm{H}_{2} \mathrm{O}_{2}$ content was found in the present study (Figure 2). It also showed that TEAC, FRAP, and NBT radical-scavenging activities slightly correlated with $\mathrm{H}_{2} \mathrm{O}_{2}$ (Figure 2), which indicated that they had little influence on $\mathrm{H}_{2} \mathrm{O}_{2}$ content.

3.4. Path Analysis. The direct effect of physiological parameters on $\mathrm{H}_{2} \mathrm{O}_{2}$ content was analyzed by PLS model. To find the indirect factors, the path analysis model was developed. As shown in Table 2, the indirect path coefficient of GSH based on DPPH was -0.3397 , which suggested that GSH was also a factor affecting $\mathrm{H}_{2} \mathrm{O}_{2}$ content. 


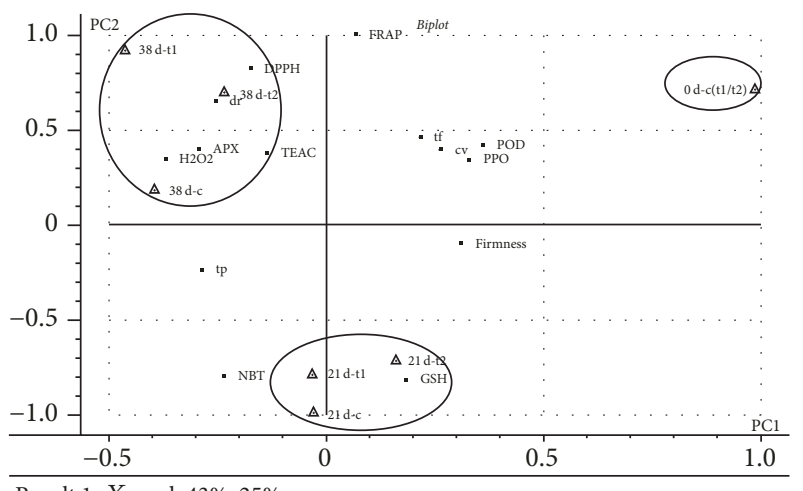

Result 1, X-expl: 43\%, 25\%

(a)

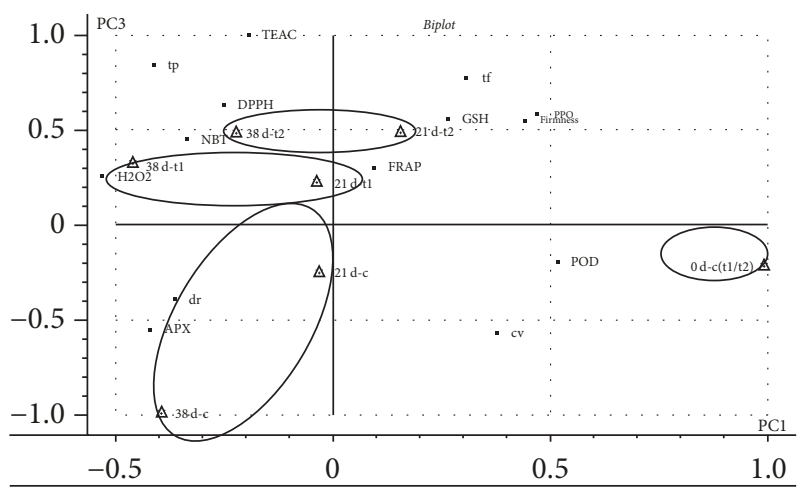

Result 1, X-expl: $43 \%, 21 \%$

(b)

Figure 1: Loadings and scores from PCA of blackberries. "c": the control group; "t1": treatment of 1-MCP; " $\mathrm{t} 2$ ": treatment of vacuum precooling; "dr": decay rate; "cv": hydroxyl radical-scavenging activity; "tp": total phenol; "tf": total flavonoids.

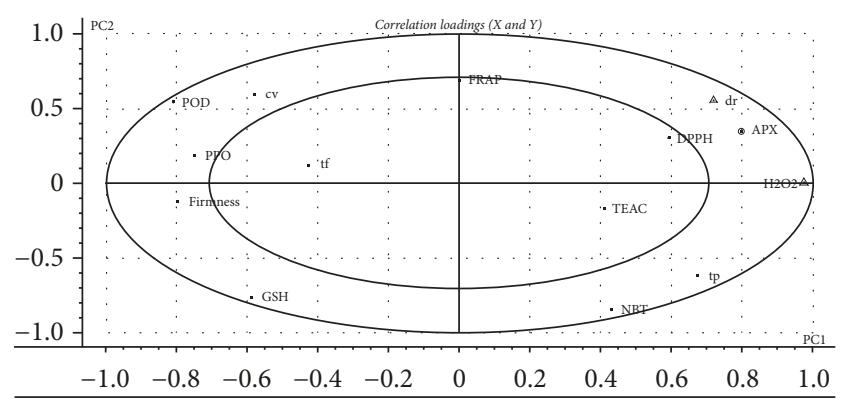

FIGURE 2: Correlation loading plot from a PLSR model. The inner and outer ellipses represent $50 \%$ and $100 \%$ of explained variance, respectively. "dr": decay rate; "cv": hydroxyl radical-scavenging activity; "tp": total phenol; "tf": total flavonoids.

\section{Conclusion}

Based on the results of PCA, vacuum precooling treatment could play a stronger role in keeping the antioxidant activities of blackberry fruit than did the 1-MCP treatment. The score of PCA also revealed that $\mathrm{H}_{2} \mathrm{O}_{2}$ was the most important variable of blackberry fruit. Results from partial least squares regression and path analysis showed that POD activity had a direct effect and GSH content had an indirect effect on $\mathrm{H}_{2} \mathrm{O}_{2}$ content, while TEAC, FRAP, and NBT radical-scavenging activities had little effect on $\mathrm{H}_{2} \mathrm{O}_{2}$ content.

\section{Conflicts of Interest}

The authors declare that there are no conflicts of interest regarding the publication of this article.

\section{Acknowledgments}

This research was supported by the National Natural Science Foundation of China (31471626), the National Science \& Technology Support Program of China (2015BAD16B06), and the Importation and Development of High-Caliber Talents Project of Beijing Municipal Institutions (CIT\&TCD201504008).

\section{References}

[1] J. Gudej and M. Tomczyk, "Determination of flavonoids, tannins and ellagic acid in leaves from RubusL. species," Archives of Pharmacal Research, vol. 27, no. 11, pp. 1114-1119, 2004.

[2] S. Y. Wang and H. Lin, "Antioxidant activity in fruits and leaves of blackberry, raspberry, and strawberry varies with cultivar and developmental stage," Journal of Agricultural and Food Chemistry, vol. 48, no. 2, pp. 140-146, 2000.

[3] I. Koca and B. Karadeniz, "Antioxidant properties of blackberry and blueberry fruits grown in the black sea region of Turkey," Scientia Horticulturae, vol. 121, no. 4, pp. 447-450, 2009.

[4] M. Joo, N. Lewandowski, R. Auras, J. Harte, and E. Almenar, "Comparative shelf life study of blackberry fruit in bio-based and petroleum-based containers under retail storage conditions," Food Chemistry, vol. 126, no. 4, pp. 1734-1740, 2011.

[5] G. A. Manganaris, I. F. Ilias, M. Vasilakakis, and I. Mignani, "The effect of hydrocooling on ripening related quality attributes and cell wall physicochemical properties of sweet cherry fruit (Prunus avium L.)," International Journal of Refrigeration, vol. 30, no. 8, pp. 1386-1392, 2007.

[6] G. Cheng, X. Duan, J. Shi et al., "Effects of reactive oxygen species on cellular wall disassembly of banana fruit during ripening," Food Chemistry, vol. 109, no. 2, pp. 319-324, 2008.

[7] Y. Imahori, M. Takemura, and J. Bai, "Chilling-induced oxidative stress and antioxidant responses in mume (Prunus mume) fruit during low temperature storage," Postharvest Biology and Technology, vol. 49, no. 1, pp. 54-60, 2008.

[8] D. Inzé and M. V. Montagu, "Oxidative stress in plants," Current Opinion in Biotechnology, vol. 6, no. 2, pp. 153-158, 1995.

[9] U. Imeh and S. Khokhar, "Distribution of conjugated and free phenols in fruits: antioxidant activity and cultivar variations," Journal of Agricultural and Food Chemistry, vol. 50, no. 22, pp. 6301-6306, 2002.

[10] Y. Y. Voon, N. Sheikh Abdul Hamid, G. Rusul, A. Osman, and S. Y. Quek, "Volatile flavour compounds and sensory properties of minimally processed durian (Durio zibethinus cv. D24) fruit during storage at $4 \circ \mathrm{C}$," Postharvest Biology and Technology, vol. 46, no. 1, pp. 76-85, 2007.

[11] H. Zheng and H. Lu, "Use of kinetic, Weibull and PLSR models to predict the retention of ascorbic acid, total phenols and antioxidant activity during storage of pasteurized pineapple juice," LWT-Food Science and Technology, vol. 44, no. 5, pp. 1273-1281, 2011. 
[12] A. Jiménez, J. A. Hernández, L. A. del Río, and F. Sevilla, "Evidence for the presence of the ascorbate-glutathione cycle in mitochondria and peroxisomes of pea leaves," Plant Physiology, vol. 114, no. 1, pp. 275-284, 1997.

[13] A. Jiang, S. P. Tian, and Y. Xu, "Effects of controlled atmospheres with high-O2 or high $\mathrm{CO} 2$ concentrations on postharvest physiology and storability of "Napoleon" sweet cherry," Acta Botanica Sinica, vol. 44, pp. 925-930, 2002.

[14] A. Guri, "Variation in glutathione and ascorbic acid content among selected cultivars of phaseolus vulgaris prior to and afer exposure to ozone," Canadian Journal of Plant Science, vol. 63, no. 3, pp. 733-737, 1983.

[15] T. Brennan and C. Frenkel, "Involvement of Hydrogen Peroxide in the Regulation of Senescence in Pear," Plant Physiology, vol. 59, no. 3, pp. 411-416, 1977.

[16] I. F. F. Benzie and J. J. Strain, "The ferric reducing ability of plasma (FRAP) as a measure of "antioxidant power": the FRAP assay," Analytical Biochemistry, vol. 239, no. 1, pp. 70-76, 1996.

[17] M. J. T. J. Arts, J. S. Dallinga, H.-P. Voss, G. R. M. M. Haenen, and A. Bast, "A critical appraisal of the use of the antioxidant capacity (TEAC) assay in defining optimal antioxidant structures," Food Chemistry, vol. 80, no. 3, pp. 409-414, 2003.

[18] M.-Y. Shon, T.-H. Kim, and N.-J. Sung, "Antioxidants and free radical scavenging activity of Phellinus baumii (Phellinus of Hymenochaetaceae) extracts," Food Chemistry, vol. 82, no. 4, pp. 593-597, 2003.

[19] C. Larrigaudière, A. P. Candan, D. Ubach, and J. Graell, "Physiological response of "Larry Ann" plums to cold storage and 1MCP treatment," Postharvest Biology and Technology, vol. 51, no. 1, pp. 56-61, 2009.

[20] F. Bamdad, M. Kadivar, and J. Keramat, "Evaluation of phenolic content and antioxidant activity of Iranian caraway in comparison with clove and BHT using model systems and vegetable oil," International Journal of Food Science \& Technology, vol. 41, no. 1, pp. 20-27, 2006.

[21] R. A. Spotts, P. L. Sholberg, P. Randall, M. Serdani, and P. M. Chen, "Effects of 1-MCP and hexanal on decay of d'Anjou pear fruit in long-term cold storage," Postharvest Biology and Technology, vol. 44, no. 2, pp. 101-106, 2007.

[22] R. Zhou, Y. Li, L. Yan, and J. Xie, "Effect of edible coatings on enzymes, cell-membrane integrity, and cell-wall constituents in relation to brittleness and firmness of Huanghua pears (Pyrus pyrifolia Nakai, cv. Huanghua) during storage," Food Chemistry, vol. 124, no. 2, pp. 569-575, 2011.

[23] S. Navabpour, K. Morris, R. Allen, E. Harrison, S. A-HMackerness, and V. Buchanan-Wollaston, "Expression of senescence-enhanced genes in response to oxidative stress," Journal of Experimental Botany, vol. 54, no. 391, pp. 2285-2292, 2003.

[24] Y. F. Xue and Z. P. Liu, "Antioxidant enzymes and physiological characteristics in two Jerusalem artichoke cultivars under salt stress," Russian Journal of Plant Physiology, vol. 55, no. 6, pp. 776-781, 2008. 

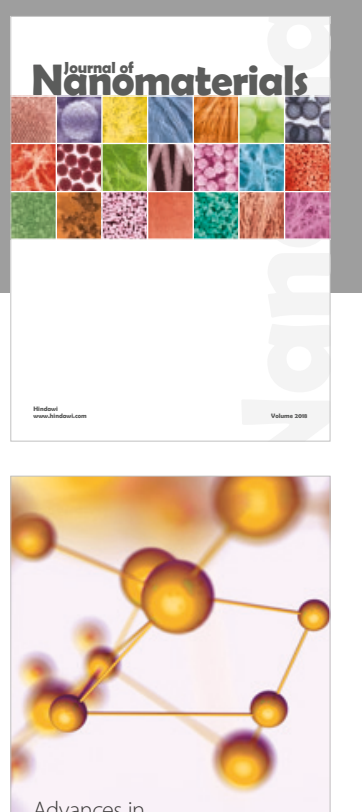

Physical Chemistry
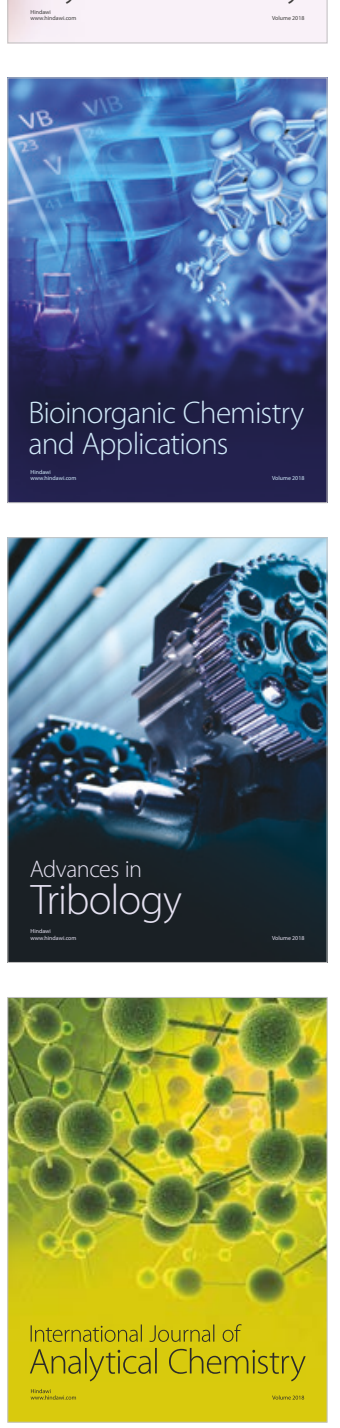

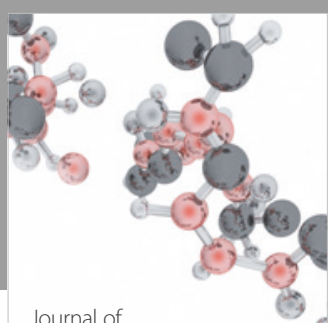

Analytical Methods

in Chemistry

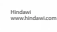

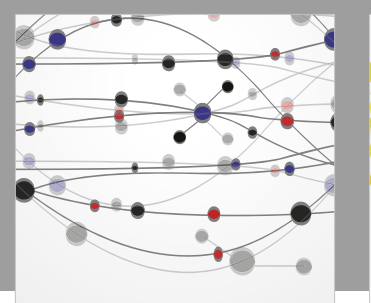

The Scientific World Journal

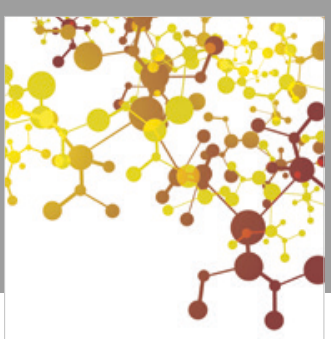

Journal of

Applied Chemistry
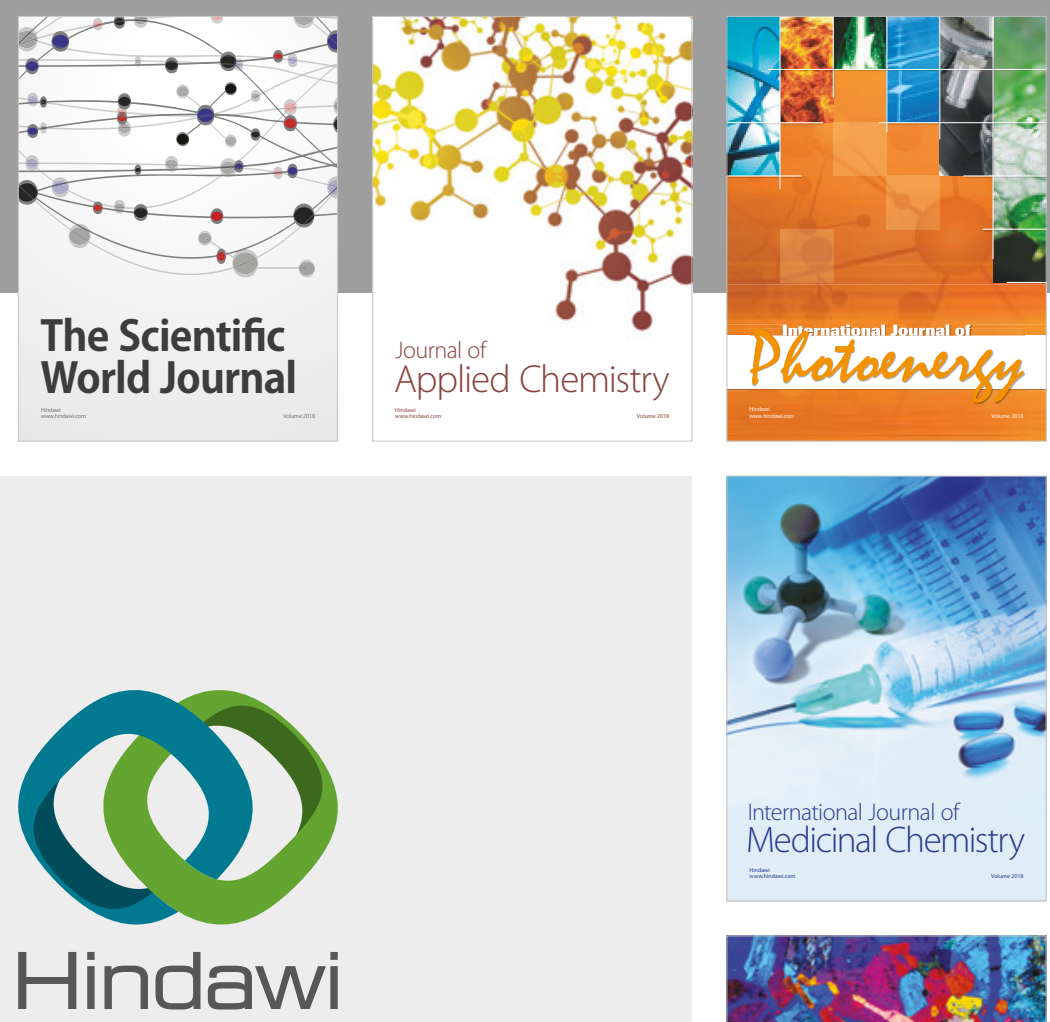

Submit your manuscripts at

www.hindawi.com
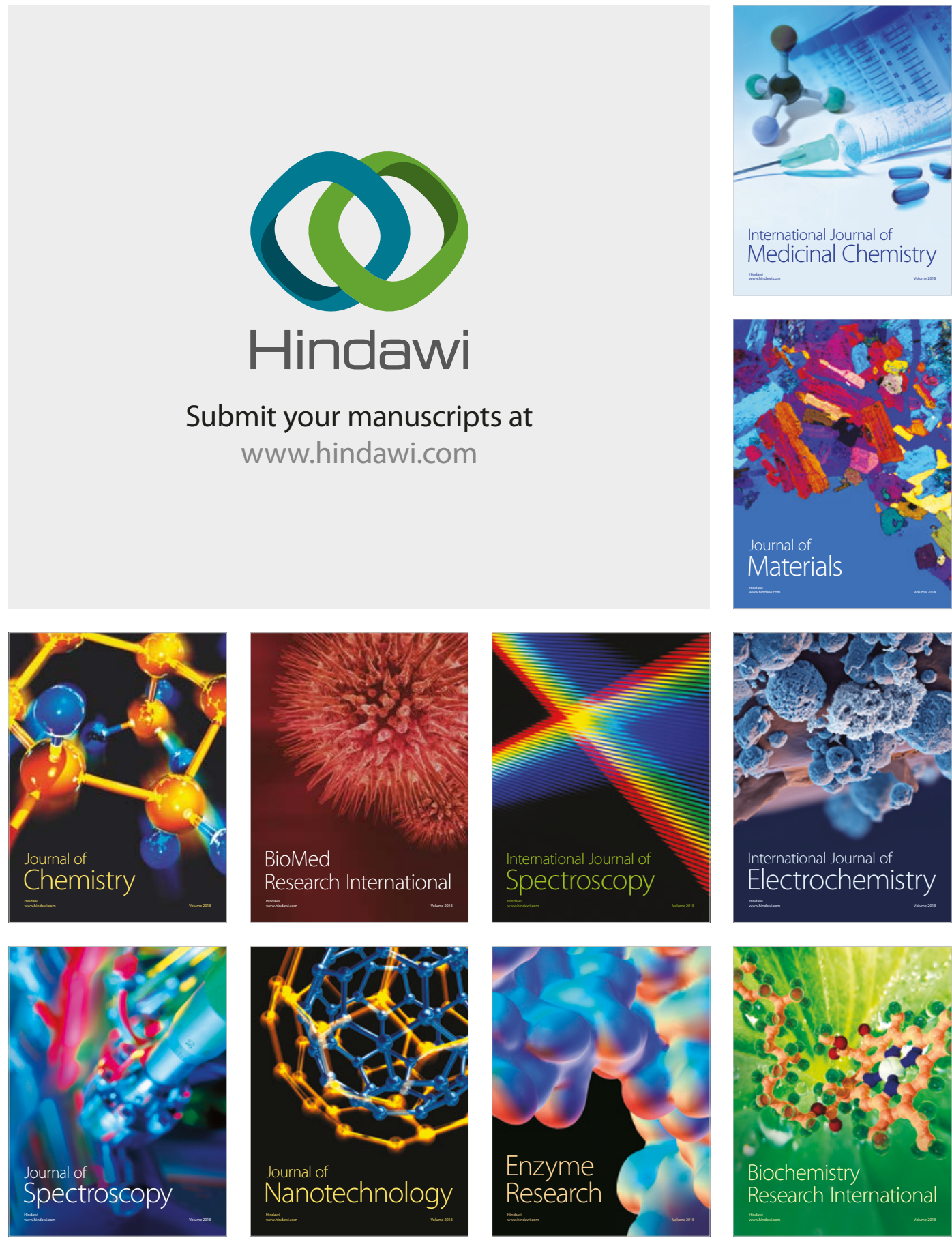
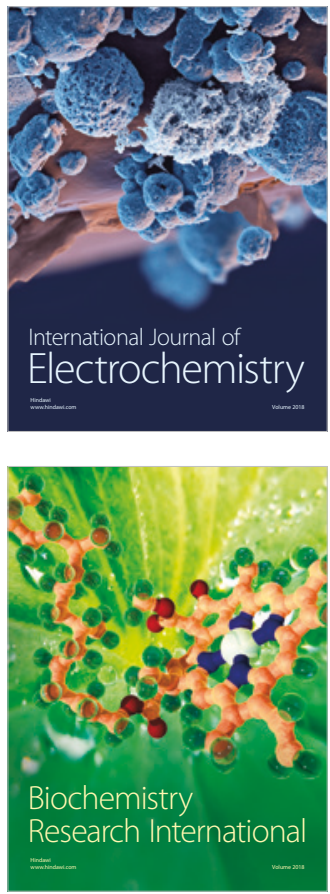